\title{
RELAÇÃO ENTRE SUCESSÃO SECUNDÁRIA, SOLO E SERAPILHEIRA EM UMA RESERVA BIOLÓGICA NO ESTADO DO RIO DE JANEIRO, BRASIL
}

\author{
RELATIONSHIP AMONG SECONDARY SUCCESSION, SOIL AND LITTER IN A BIOLOGICAL \\ RESERVE IN RIO DE JANEIRO STATE, BRAZIL
}

\author{
Rodrigo Camara $^{1}$ Vinicius Duncan Silva ${ }^{2}$ Geovana Carla Girondi Delaqua ${ }^{2}$ Cinthia Pinheiro Lisbôa ${ }^{3}$ \\ Dora Maria Villela ${ }^{4}$
}

\section{RESUMO}

A ciclagem de nutrientes é influenciada pelo estágio sucessional. Contudo, existem divergências quanto ao padrão desta dinâmica. No presente estudo, objetivou-se avaliar os atributos químicos do solo superficial e da serapilheira produzida em dois plantios abandonados do eucalipto Corymbia citriodora em diferentes estágios de sucessão secundária de espécies nativas de Mata Atlântica (PJ: plantio jovem; PM: plantio maduro), na Reserva Biológica União, Rio de Janeiro. Testou-se a hipótese de que ocorre o incremento da concentração de nutrientes na camada superficial de solo e na serapilheira, da produção de serapilheira e do aporte de nutrientes para o solo via serapilheira, em função do avanço da sucessão. Em cinco parcelas $(5 \mathrm{~m} \times 20 \mathrm{~m})$ em PJ e PM, foram realizadas amostragens da camada superficial do solo $(0-10 \mathrm{~cm}$; estações seca/2008, chuvosa/2008, seca/2009 e chuvosa/2010) e da serapilheira (coletores com $0,49 \mathrm{~m}^{2} ; 1,0 \mathrm{~m}$ acima do solo; coletas quinzenais; período amostral de 366 dias). A camada superficial do solo na área PM apresentou maiores concentrações de $\mathrm{C}$ e $\mathrm{N}$ totais, $\mathrm{H}+\mathrm{Al}$ e $\mathrm{Mn}$. Por outro lado, os valores de $\mathrm{pH}$, razão $\mathrm{C} / \mathrm{N}$, concentrações de $\mathrm{K}, \mathrm{Fe}$ e $\mathrm{Zn}$ foram maiores na camada de solo superficial na área PJ. Não se detectou padrão claro para as concentrações de $\mathrm{P}$ e $\mathrm{Cu}$ no solo. A produção anual de serapilheira foi maior na área $\mathrm{PM}$, que apresentou maiores concentrações de $\mathrm{N}$ total e $\mathrm{Mg}$, enquanto na área $\mathrm{PJ}$ foram verificados maiores valores da razão $\mathrm{C} / \mathrm{N}$ e concentrações de $\mathrm{Pe} \mathrm{Ca}$. Não houve variação para $\mathrm{C}$ total na serapilheira. Os aportes de $\mathrm{C}, \mathrm{N}, \mathrm{P}, \mathrm{K}$ e Mg foram maiores na serapilheira na área PM, e não houve diferenças entre as áreas PJ e PM para o aporte de Ca. Corroboramos em parte a hipótese testada em relação ao teor de nutrientes na camada superficial do solo, serapilheira e aporte de nutrientes, e corroboramos integralmente a hipótese no que se refere à produção de serapilheira.

Palavras-chave: ciclagem de nutrientes; Corymbia citriodora; regeneração natural.

\section{ABSTRACT}

The nutrient cycling is influenced by the successional stage. However, there is disagreement in relation to the pattern of this dynamic. The present study aimed to evaluate the chemical attributes of the topsoil and litterfall in two abandoned plantations of the eucalyptus Corymbia citriodora in different stages of Atlantic Rainforest succession (PJ: young plantation; PM: mature plantation) at the União Biological Reserve, RJ. We tested the hypothesis that there is an increase in the nutrient contents in the topsoil and litterfall, the amount of litterfall and nutrient input to the soil, as the process of forest succession advances. We sampled the topsoil (depth of 0-10 cm; dry season/2008, rainy season/2008, dry season/2009, rainy season/2010) and litterfall ( $0.49 \mathrm{~m}^{2}$ traps; $1.0 \mathrm{~m}$ above the forest floor; twice a month; 366 days $)$ in five plots

1 Engenheiro Agrônomo, Dr., Pós-Doutorando pela Universidade Federal Rural do Rio de Janeiro, Rod. BR 465, km 07, s/n, CEP 23890-000, Seropédica (RJ), Brasil. Bolsista da CAPES. rcamara73@gmail.com

2 Biólogo, MSc., Universidade Estadual do Norte Fluminense Darcy Ribeiro, 2000, CEP 28013-600, Campos dos Goytacazes (RJ), Brasil. vini.duncan@gmail.com / geovanagirondi@gmail.com

3 Bióloga, Universidade Estadual do Norte Fluminense Darcy Ribeiro, 2000, CEP 28013-600, Campos dos Goytacazes (RJ), Brasil. cinthia-lisnet@hotmail.com

4 Bióloga, Dra ${ }^{\mathrm{a}}$, Professora Associada do Laboratório de Ciências Ambientais, Universidade Estadual do Norte Fluminense Darcy Ribeiro, 2000, CEP 28013-600, Campos dos Goytacazes (RJ), Brasil. dora@uenf.br 
$(5 \mathrm{~m} \times 20 \mathrm{~m}$ ) in the areas of PJ and PM. The topsoil in the PM area presented higher content of total $\mathrm{C}$ and $\mathrm{N}, \mathrm{H}+\mathrm{Al}$, and $\mathrm{Mn}$. On the other hand, the values of $\mathrm{pH}, \mathrm{C} / \mathrm{N}$ ratio and content of $\mathrm{K}, \mathrm{Fe}$, and $\mathrm{Zn}$ were higher in the topsoil in the PJ area. No clear pattern was detected in terms of the $\mathrm{P}$ and $\mathrm{Cu}$ content in the topsoil. The annual litterfall was higher in the PM area, which presented higher content of total $\mathrm{N}$ and $\mathrm{Mg}$, while higher $\mathrm{C} / \mathrm{N}$ ratio and content of both $\mathrm{P}$ and $\mathrm{Ca}$ occurred in the $\mathrm{PJ}$ area. We did not detect differences in terms of total $\mathrm{C}$ in litterfall. The input of C, N, P, K and Mg to the soil were higher by litterfall in the area of PM, and there were no differences between PJ and PM in relation to the Ca input. We partly corroborated the tested hypothesis in relation to the nutrient content in topsoil, litterfall and nutrient input, and we completely corroborated the hypothesis in terms of litterfall.

Keywords: nutrient cycling; Corymbia citriodora; natural regeneration.

\section{INTRODUÇÃO}

O solo é um sistema dinâmico no qual ocorrem processos vitais nos ecossistemas terrestres, tais como a ciclagem biogeoquímica de nutrientes (NANNIPIERI et al., 2003). A serapilheira apresenta papel de destaque nesta dinâmica, uma vez que esta aporta quantidades relevantes de nutrientes antes encerrados na biomassa florestal para o solo, por meio da mineralização, os quais podem ser novamente disponibilizados para as plantas (CULLINGS et al., 2003). Este impacto direto da serapilheira ocorre de maneira mais contundente nos primeiros $10 \mathrm{~cm}$ de solo, que é a camada do solo que está em contato mais íntimo com a mesma, e é onde se concentra a maior parte das raízes finas absorventes, nos ecossistemas florestais (MORAES et al., 2008).

Alguns fatores influenciam o aporte de nutrientes via serapilheira para o solo florestal, tais como a estrutura e composição da comunidade de plantas (PAOLI; CURRAN; ZAK, 2006). Estas, por sua vez, variam conforme o estágio sucessional, já que florestas em estágio sucessional mais avançado apresentam maiores biomassa, riqueza e diversidade de espécies arbóreas (BOEGER; WISNIEWSKI; REISSMANN, 2005). Por um lado, o maior desenvolvimento estrutural nestes ecossistemas é responsável por um maior estoque de nutrientes na biomassa florestal, em detrimento do solo, quando comparado com florestas em estágios sucessionais iniciais (LUGO; HELMER, 2004; BAUTISTA-CRUZ; CASTILLO, 2005; MORAES et al., 2008; NOH et al., 2010). Tal evento é potencializado pelo fato de que a dinâmica de retranslocação interna de nutrientes é mais eficiente em florestas maduras, de modo que este mecanismo favorece a conservação da maior parte destes elementos na biomassa vegetal (VITOUSEK; SANDFORD JUNIOR, 1986; FERREIRA et al., 2006).

Por outro lado, a maior complexidade estrutural das florestas mais maduras se reflete na maior produção de serapilheira (BARBOSA; FARIA, 2006; PINTO et al., 2008) e no maior acúmulo de serapilheira sobre a superfície do solo (LUGO; HELMER, 2004). Esta serapilheira comumente apresenta maiores concentrações de nutrientes, em comparação com aquela produzida em estágios iniciais (TOLEDO; PEREIRA; MENEZES, 2002; PINTO; MARQUES, 2003; VASCONCELOS; LAURANCE, 2005; BARBOSA; FARIA, 2006; CALVI; PEREIRA; ESPÍNDULA JÚNIOR, 2009; PINTO et al., 2009). Esse padrão é consequência da produção de uma serapilheira mais heterogênea pelas comunidades vegetais com maior diversidade, nas florestas maduras (NEGRETE-YANKELEVICH et al., 2007). Com isto, pode-se observar um maior estoque de nutrientes no solo nestes ecossistemas (PINTO; MARQUES, 2003; PINTO et al., 2009).

Portanto, há divergências no âmbito das informações disponíveis a respeito das alterações que ocorrem nos atributos edáficos e da serapilheira, ao longo do desenvolvimento ecossistêmico. O presente estudo objetivou contribuir para o levantamento de informações acerca destas alterações. Para tanto, avaliaram-se os atributos químicos da camada superficial do solo e da serapilheira produzida em dois plantios abandonados de eucalipto Corymbia citriodora em diferentes estágios de sucessão de espécies nativas de Mata Atlântica, na Reserva Biológica União, RJ. Testou-se a hipótese de que ocorrem o incremento: (1) da concentração de nutrientes na camada superficial do solo e na serapilheira, (2) da produção de serapilheira e (3) do aporte de nutrientes para o solo via serapilheira, com o avançar da sucessão secundária.

Ci. Fl., v. 28, n. 2, abr .- jun., 2018 


\section{MATERIAL E MÉTODOS}

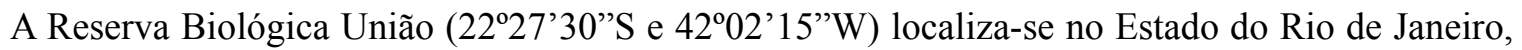
Brasil, e apresenta área total de aproximadamente 3.121 ha (IBAMA, 2007). A maior parte é composta por Mata Atlântica (2.400 ha), e o restante da área é representado por plantios de eucalipto com diferentes idades de instalação (215 ha), além de pastagens, área industrial, estradas, gasodutos e outros tipos de uso do solo (506 ha). O clima predominante na região é do tipo Aw, que significa tropical úmido com inverno seco (KÖPPEN, 1948). A temperatura média anual é de $22^{\circ} \mathrm{C}$, enquanto a precipitação pluviométrica total anual é de $2.337 \mathrm{~mm} \mathrm{ano}^{-1}$, cuja maior parte ( $89 \%$ do total) ocorre entre outubro e abril (CAMARA; CORREIA; VILLELA, 2012).

As avaliações de solo e serapilheira foram realizadas em dois plantios do eucalipto Corymbia citriodora (Hook.) K. D. Hill e L. A. S. Johnson com diferentes idades de implantação: Plantio Jovem (PJ) e Plantio Maduro (PM), instalados em 1991 e 1968, respectivamente. No PM (11,4 ha), o espaçamento de plantio é de 3,0 m x 3,0 m, e a densidade de árvores de Corymbia citriodora é de 661 indivíduos ha ${ }^{-1}$, ao passo que no PJ (7,2 ha) é de 1,5 $\mathrm{m} \mathrm{x} \mathrm{3,0} \mathrm{m} \mathrm{e} 611$ indivíduos ha ${ }^{-1}$, respectivamente (IBAMA, 2007). Ambos os plantios, que foram implantados em solo da classe Argissolo Vermelho-Amarelo distrófico latossólico (MIRANDA; CANELLAS; NASCIMENTO, 2007), estão abandonados desde 1996 e foram implantados antes da constituição da Reserva em 1998. Como resultado do abandono, iniciou-se a sucessão de espécies arbóreas e arbustivas nativas de Mata Atlântica, no sub-bosque, sendo que o dossel é predominantemente formado por indivíduos de Corymbia citriodora. No PM, o estágio sucessional é mais avançado (densidade: 1.010 indivíduos ha ${ }^{-1}$; área basal: $9,9 \mathrm{~m}^{2} \mathrm{ha}^{-1}$; riqueza: 17 espécies; índice de diversidade de Shannon: $\mathrm{H}^{\prime}=$ 2,1), em comparação com o PJ (densidade: 10 indivíduos ha ${ }^{-1}$; área basal: $0,03 \mathrm{~m}^{2} \mathrm{ha}^{-1}$; riqueza: 1 espécie; H': 0) (EVARISTO; BRAGA; NASCIMENTO, 2011).

As amostragens de solo e serapilheira foram realizadas em cinco parcelas ( $5 \mathrm{~m}$ x $20 \mathrm{~m}$ ) estabelecidas em ambos os plantios de eucalipto, as quais foram demarcadas em 2001 para a realização de outros trabalhos (EVARISTO; BRAGA; NASCIMENTO, 2011). Cinco amostras simples da camada superficial de solo (0$10 \mathrm{~cm}$ ) foram coletadas em cada parcela, com o auxílio de trado do tipo "caneca", e transferidas para sacos plásticos devidamente identificados. No laboratório, estas amostras foram transferidas para recipientes de alumínio, para secagem em estufa de circulação forçada de ar $\left(40^{\circ} \mathrm{C}, 72 \mathrm{~h}\right)$. Em seguida, as amostras simples foram reunidas para obtenção de uma amostra composta por parcela. Cada amostra composta foi destorroada, peneirada ( $2 \mathrm{~mm}$ ), homogeneizada e armazenada em saco plástico identificado, obtendo-se assim a terra fina seca em estufa (TFSE), até o momento da realização das análises químicas. A amostragem de solo foi realizada em quatro períodos: estações seca/2008, chuvosa/2008, seca/2009 e chuvosa/2010.

A serapilheira produzida foi avaliada por meio de coletores constituídos por uma estrutura de alumínio de 70,0 cm x 70,0 cm (área útil de $0,49 \mathrm{~m}^{2}$ ) revestida por uma malha de náilon de $1 \mathrm{~mm}$, com 20,0 $\mathrm{cm}$ de profundidade, sustentada por estacas de madeira de aproximadamente 1,0 $\mathrm{m}$ de altura, em relação à superfície do solo. Em cada parcela foram distribuídos três coletores, de maneira aleatória estratificada, em 18 de novembro de 2009 (início da estação chuvosa). O material contido nos coletores foi recolhido quinzenalmente, no período de 03/dezembro/2009 a 19/novembro/2010 (período amostral de 366 dias), e transferido para sacos de papel. No laboratório, este material foi seco em estufa de circulação forçada de ar $\left(60^{\circ} \mathrm{C}, 72 \mathrm{~h}\right)$, imediatamente após cada data de coleta (ALLEN, 1989). Em seguida, a serapilheira foi triada nas frações: (1) folhas de Corymbia citriodora, (2) folhas de espécies nativas, (3) galhos finos (diâmetro $\leq 2$ $\mathrm{cm}$ ) e cascas do tronco, (4) miscelânea (flores, frutos, sementes e material vegetal e animal não identificável com diâmetro $<2 \mathrm{~mm}$ ). Após este procedimento, as frações obtidas em cada coletor foram novamente secas em estufa e reunidas em uma amostra composta/parcela, para a obtenção da massa seca em balança digital com duas casas decimais.

Nas amostras de solo, foram determinados o $\mathrm{pH}$ em $\mathrm{H}_{2} \mathrm{O}$, acidez potencial $(\mathrm{H}+\mathrm{Al}), \mathrm{Al}$ trocável $\left(\mathrm{Al}^{+3}\right)$ e $\mathrm{P}$ disponível no solo, de acordo com Embrapa (1997). As concentrações de $\mathrm{C}$ e $\mathrm{N}$ totais foram determinadas diretamente pelo autoanalisador CHN/S (Perkin Elmer 2400), a partir de subamostras (2-4 $\mathrm{mg}$ ) de TFSE previamente maceradas em gral com auxílio de pistilo, e acondicionadas em eppendorfs (ALLEN, 1989). No solo, os macronutrientes trocáveis $\left(\mathrm{K}^{+}, \mathrm{Ca}^{+2}, \mathrm{Mg}^{+2}\right)$, que foram avaliados nas quatro datas de coleta, e os micronutrientes trocáveis $\left(\mathrm{Cu}^{+2}, \mathrm{Fe}^{+2}, \mathrm{Mn}^{+2}, \mathrm{Zn}^{+2}\right)$, que foram avaliados nas duas últimas 
datas de coleta, foram extraídos segundo Allen (1989), e determinados por espectrofotometria de emissão por plasma induzido (ICP/AES-Varian Liberty Series II).

Não houve deteç̧ão de Ca e Mg no solo do PM, em nenhuma das quatro épocas de coleta. Portanto, alterou-se o procedimento analítico (ALLEN, 1989) com o objetivo de se detectarem tais nutrientes neste material. Desta maneira, empregou-se $20 \mathrm{~g}$ de TFSE (o dobro do preconizado pela metodologia adotada), que ficou em contato com a solução extratora de cátions (acetato de amônia $1 \mathrm{~mol} \mathrm{~L}^{-1}$, ajustada a valores de pH médio do solo com ácido acético glacial) por aproximadamente $12 \mathrm{~h}$, ao invés de se proceder à lixiviação imediata por meio de cinco adições sucessivas de $20 \mathrm{~mL}$ da mesma. Mesmo após este procedimento, não houve detecção de $\mathrm{Ca}$ e $\mathrm{Mg}$ nas amostras da camada superficial de solo da área de PM, pelo ICP. Isto ocorreu em função de concentrações muito baixas destes elementos, que no caso de Ca foi $<0,24 \mathrm{mmol} \mathrm{kg}_{\mathrm{c}}$ ${ }^{1}$, que é o limite inferior de detecção deste elemento no ICP, segundo a Central Analítica. Esta não forneceu o limite inferior de detecção de $\mathrm{Mg}$, em extratos de solo.

Para as análises químicas realizadas na serapilheira, as frações obtidas em cada parcela foram reunidas a cada quatro meses consecutivos, para a determinação das concentrações de $\mathrm{C}$ e $\mathrm{N}$ totais, ou a cada dois meses consecutivos, para a determinação das concentrações de P, K, Ca e Mg. Este procedimento visou otimizar o número de amostras para as análises químicas. Em seguida, as amostras foram moídas em moinho elétrico. A determinação das concentrações de $\mathrm{C} \mathrm{e} \mathrm{N}$ totais foram realizadas de maneira análoga ao que ocorreu para o solo. Para a extração de P, K, Ca e Mg, subamostras (aproximadamente 0,20 g de massa seca em estufa) das frações de serapilheira passaram por digestão ácida (ALLEN, 1989), e no extrato assim obtido foram determinadas as suas concentrações em ICP. Todo o procedimento de secagem, pesagem e análises químicas do solo e serapilheira ocorreram no Laboratório de Ciências Ambientais (LCA) da Universidade Estadual do Norte Fluminense (UENF), Campos dos Goytacazes-RJ.

Os valores médios dos atributos químicos do solo, da serapilheira e do aporte de elementos ao solo via serapilheira foram submetidos à análise de variância (ANOVA) pelo teste de Levene. Quando as variâncias apresentaram homogeneidade, os valores médios foram comparados por meio do teste $t$ de Student $(\mathrm{p} \leq 0,05)$; caso contrário, foram comparados pelo teste não paramétrico de Mann-Whitney $(\mathrm{p} \leq 0,05)(Z A R$, 1996). Os valores de produção ( $\mathrm{Mg} \mathrm{ha}^{-1}$ ano $\left.^{-1}\right)$ de serapilheira anual (total e frações) foram comparados por meio de análise de variância agrupada (ANOVA Nested Design). Para tanto, consideraram-se as réplicas (n = 5 parcelas/área) como o fator randômico dentro de cada plantio, o qual foi considerado como o fator fixo (ZAR, 1996). Estas avaliações foram realizadas com o auxílio do software Statistica versão 7.0.

\section{RESULTADOS E DISCUSSÃO}

Verificaram-se dois padrões opostos para o efeito do estágio sucessional sobre os atributos químicos da camada superficial do solo $(0-10 \mathrm{~cm})$ (Tabela 1$)$. De uma maneira geral, foram maiores as concentrações de $\mathrm{Mn}, \mathrm{C}$ e $\mathrm{N}$ totais, e de $\mathrm{H}+\mathrm{Al}$ e $\mathrm{Al}$, as quais se refletiram em menores valores de $\mathrm{pH}$, na área do $\mathrm{PM}$. Por outro lado, as concentrações de $\mathrm{K}$, Fe e $\mathrm{Zn}$ foram maiores na área do PJ, que também apresentou maiores valores para a razão $\mathrm{C} / \mathrm{N}$. Não foi verificado efeito do estágio sucessional sobre a disponibilidade de $\mathrm{P} \mathrm{e}$ $\mathrm{Cu}$ na camada superficial do solo. Jia et al. (2005) e Noh et al. (2010) também verificaram o aumento das concentrações de $\mathrm{C}$ e $\mathrm{N}$ em função da sucessão secundária em ecossistemas florestais na China e Coreia, respectivamente. Durante este processo, ocorre o incremento do estoque de matéria orgânica nos solos florestais (NEGRETE-YANKELEVICH et al., 2007). Como consequência, observa-se a formação de um microclima favorável para os organismos decompositores, que concorre para a liberação dos nutrientes da serapilheira e o aumento do estoque destes no solo (PINTO; MARQUES, 2003; PINTO et al., 2009).

As maiores concentrações de $\mathrm{C}$ e $\mathrm{N}$ totais na camada superficial na área de PM foram reflexo do maior aporte destes elementos decorrentes da maior produção total de serapilheira, além da participação mais relevante das espécies nativas na produção de serapilheira foliar neste ecossistema, conforme levantamento do presente trabalho. De fato, a maior participação de folhas de espécies nativas na serapilheira total se refletiu no incremento do aporte de $\mathrm{C}$ e $\mathrm{N}$ em 16 e 25 vezes maior, respectivamente, na área de PM em comparação com a serapilheira total na área PJ. Portanto, na área PM, a serapilheira foliar mais heterogênea contribuiu para que as concentrações de $\mathrm{C}$ e $\mathrm{N}$ totais fossem maiores no solo superficial. Acredita-se que este fato também tenha sido responsável pelas maiores concentrações de Mn na camada de solo superficial 
na área PM, embora não tenham sido levantados dados sobre o aporte de Mn via serapilheira.

A menor razão $\mathrm{C} / \mathrm{N}$ na camada superficial de solo na área $\mathrm{PM}$ demonstrou que a matéria orgânica proveniente da serapilheira foliar das espécies nativas apresenta contribuição relativamente mais importante para a dinâmica de nutrientes, do que aquela aportada ao solo na área PJ. Esse padrão deve-se à maior qualidade química da serapilheira foliar das espécies nativas (maiores concentrações médias de $\mathrm{N}$ e $\mathrm{Mg}$ e menor razão $\mathrm{C} / \mathrm{N}$ ), que se refletiu na maior qualidade química da serapilheira total, o que, aliado à maior produção desta, levou aos maiores aportes destes nutrientes ao solo na área do PM.

TABELA 1: Atributos químicos do solo superficial (desvio padrão) nos plantios jovem (PJ) e maduro (PM) do eucalipto Corymbia citriodora, Reserva Biológica União, RJ.

TABLE 1: Soil chemical attributes (standard deviation) in young (PJ) and mature (PM) plantations of Corymbia citriodora, União Biological Reserve, RJ state.

\begin{tabular}{|c|c|c|c|c|c|c|c|c|c|c|}
\hline \multirow[t]{2}{*}{ Área } & $\begin{array}{l}\mathrm{C} \\
--\mathrm{g} \mathrm{k}^{-}\end{array}$ & $\mathrm{N}$ & $\mathrm{C} / \mathrm{N}$ & $\begin{array}{l}\mathrm{P} \\
--\mathrm{mg}\end{array}$ & $\begin{array}{c}\mathrm{K} \\
\mathrm{dm}^{-3}-- \\
\end{array}$ & $\mathrm{Ca}$ & $\begin{array}{l}\mathrm{Mg} \\
--\mathrm{cmo} \\
\end{array}$ & $\begin{array}{c}\mathrm{H}+\mathrm{Al} \\
\mathrm{dm}^{-3}-\cdots\end{array}$ & $\begin{array}{l}\mathrm{Al} \\
-- \\
-\end{array}$ & $\begin{array}{c}\mathrm{pH} \\
\mathrm{H}_{2} \mathrm{O}\end{array}$ \\
\hline & \multicolumn{10}{|c|}{ Seca/2008 } \\
\hline PJ & $\begin{array}{c}24,40 a \\
(4,16)\end{array}$ & $\begin{array}{c}3,15 \\
(0,35)\end{array}$ & $\begin{array}{l}7,73 a \\
(0,70)\end{array}$ & $\begin{array}{c}1,84 \\
(0,72)\end{array}$ & $\begin{array}{c}89,13 \\
(16,79)\end{array}$ & $\begin{array}{l}11,06 \\
(6,25)\end{array}$ & $\begin{array}{l}13,05 \\
(4,19)\end{array}$ & $\begin{array}{l}3,41 \mathrm{a} \\
(0,45)\end{array}$ & $\begin{array}{l}1,99 a \\
(0,67)\end{array}$ & $\begin{array}{l}4,74 a \\
(0,44)\end{array}$ \\
\hline PM & $\begin{array}{c}28,39 b \\
(4,96)\end{array}$ & $\begin{array}{c}3,39 \\
(0,30)\end{array}$ & $\begin{array}{c}8,38 \mathrm{~b} \\
(1,27)\end{array}$ & $\begin{array}{c}3,12 \\
(2,25)\end{array}$ & $\begin{array}{c}74,89 \\
(14,92)\end{array}$ & nd & nd & $\begin{array}{l}5,28 \mathrm{~b} \\
(0,88)\end{array}$ & $\begin{array}{l}4,70 \mathrm{~b} \\
(0,76)\end{array}$ & $\begin{array}{l}3,61 b \\
(0,75)\end{array}$ \\
\hline \multicolumn{11}{|c|}{ Chuvosa/2008 } \\
\hline PJ & $\begin{array}{l}23,91 \\
(2,26)\end{array}$ & $\begin{array}{l}1,06 a \\
(0,28)\end{array}$ & $\begin{array}{c}23,74 \mathrm{a} \\
(5,78)\end{array}$ & $\begin{array}{l}4,84 a \\
(1,93)\end{array}$ & $\begin{array}{c}86,02 \\
(24,04)\end{array}$ & $\begin{array}{l}14,66 \\
(7,74)\end{array}$ & $\begin{array}{l}16,40 \\
(4,03)\end{array}$ & $\begin{array}{l}3,32 a \\
(0,66)\end{array}$ & $\begin{array}{r}1,59 a \\
(0,65)\end{array}$ & $\begin{array}{l}5,27 \mathrm{a} \\
(0,22)\end{array}$ \\
\hline \multirow[t]{2}{*}{ PM } & $\begin{array}{c}27,18 \\
(7,98)\end{array}$ & $\begin{array}{l}1,81 b \\
(0,66)\end{array}$ & $\begin{array}{c}15,48 b \\
(2,46)\end{array}$ & $\begin{array}{l}1,50 \mathrm{~b} \\
(0,22)\end{array}$ & $\begin{array}{c}92,22 \\
(19,84)\end{array}$ & nd & nd & $\begin{array}{l}5,29 \mathrm{~b} \\
(0,61)\end{array}$ & $\begin{array}{l}4,58 \mathrm{~b} \\
(0,59)\end{array}$ & $\begin{array}{l}4,23 b \\
(0,11)\end{array}$ \\
\hline & \multicolumn{10}{|c|}{ Seca/2009 } \\
\hline PJ & $\begin{array}{l}16,59 a \\
(3,23)\end{array}$ & $\begin{array}{l}0,81 \mathrm{a} \\
(0,34)\end{array}$ & $\begin{array}{c}22,05 a \\
(4,54)\end{array}$ & $\begin{array}{c}0,44 \\
(0,20)\end{array}$ & $\begin{array}{l}87,18 \mathrm{a} \\
(20,10)\end{array}$ & $\begin{array}{l}18,20 \\
(6,77)\end{array}$ & $\begin{array}{l}18,02 \\
(5,66)\end{array}$ & $\begin{array}{c}6,28 \\
(0,55)\end{array}$ & $\begin{array}{l}1,49 a \\
(0,70)\end{array}$ & $\begin{array}{l}5,31 \mathrm{a} \\
(0,20)\end{array}$ \\
\hline \multirow[t]{2}{*}{ PM } & $\begin{array}{c}26,74 b \\
(7,51)\end{array}$ & $\begin{array}{l}3,13 b \\
(0,52)\end{array}$ & $\begin{array}{l}8,52 b \\
(1,65)\end{array}$ & $\begin{array}{c}0,52 \\
(0,13) \\
\end{array}$ & $\begin{array}{l}69,19 \mathrm{~b} \\
(21,42) \\
\end{array}$ & nd & nd & $\begin{array}{c}5,66 \\
(1,32) \\
\end{array}$ & $\begin{array}{l}4,25 b \\
(0,43) \\
\end{array}$ & $\begin{array}{l}4,27 \mathrm{~b} \\
(0,08) \\
\end{array}$ \\
\hline & \multicolumn{10}{|c|}{ Chuvosa/2010 } \\
\hline PJ & $\begin{array}{l}23,06 \\
(3,78)\end{array}$ & $\begin{array}{c}0,59 \mathrm{a} \\
(0,20)\end{array}$ & $\begin{array}{c}41,86 a \\
(9,42)\end{array}$ & $\begin{array}{c}0,58 \mathrm{a} \\
(0,16)\end{array}$ & $\begin{array}{c}85,96 a \\
(16,66)\end{array}$ & $\begin{array}{c}12,18 \\
(5,08)\end{array}$ & $\begin{array}{l}13,68 \\
(2,96)\end{array}$ & $\begin{array}{l}3,68 \mathrm{a} \\
(0,53)\end{array}$ & $\begin{array}{l}2,58 a \\
(0,87)\end{array}$ & $\begin{array}{l}5,19 \mathrm{a} \\
(0,17)\end{array}$ \\
\hline PM & $\begin{array}{l}26,50 \\
(7,21)\end{array}$ & $\begin{array}{c}0,97 \mathrm{~b} \\
(0,33)\end{array}$ & $\begin{array}{c}28,52 \mathrm{~b} \\
(5,92)\end{array}$ & $\begin{array}{l}1,01 b \\
(0,25)\end{array}$ & $\begin{array}{c}44,92 \mathrm{~b} \\
(15,48)\end{array}$ & nd & nd & $\begin{array}{l}5,21 \mathrm{~b} \\
(0,79)\end{array}$ & $\begin{array}{l}4,47 \mathrm{~b} \\
(0,52)\end{array}$ & $\begin{array}{l}5,01 \mathrm{~b} \\
(0,01)\end{array}$ \\
\hline \multirow[t]{2}{*}{ Área } & $\mathrm{Cu}$ & $\mathrm{Fe}$ & $\mathrm{Mn}$ & $\mathrm{Zn}$ & & & $\mathrm{Cu}$ & $\mathrm{Fe}$ & $\mathrm{Mn}$ & $\mathrm{Zn}$ \\
\hline & \multicolumn{4}{|c|}{ - } & & & \multicolumn{4}{|c|}{ - } \\
\hline PJ & $\begin{array}{l}0,10 \mathrm{a} \\
(0,01)\end{array}$ & $\begin{array}{l}12,33 a \\
(2,26)\end{array}$ & $\begin{array}{c}0,12 \mathrm{a} \\
(0,03)\end{array}$ & $\begin{array}{c}0,10 \mathrm{a} \\
(0,03)\end{array}$ & & & $\begin{array}{l}0,10 \mathrm{a} \\
(0,02)\end{array}$ & $\begin{array}{l}12,06 a \\
(2,63)\end{array}$ & $\begin{array}{l}0,12 \mathrm{a} \\
(0,04)\end{array}$ & $\begin{array}{l}0,09 a \\
(0,03)\end{array}$ \\
\hline PM & $\begin{array}{l}0,14 \mathrm{~b} \\
(0,03)\end{array}$ & $\begin{array}{c}3,46 \mathrm{~b} \\
(0,55)\end{array}$ & $\begin{array}{l}0,77 b \\
(0,38)\end{array}$ & $\begin{array}{l}0,06 \mathrm{~b} \\
(0,01)\end{array}$ & & & $\begin{array}{l}0,07 \mathrm{~b} \\
(0,02)\end{array}$ & $\begin{array}{l}3,63 b \\
(0,93)\end{array}$ & $\begin{array}{l}0,80 \mathrm{~b} \\
(0,48)\end{array}$ & $\begin{array}{l}0,03 b \\
(0,02)\end{array}$ \\
\hline
\end{tabular}

Em que: Valores médios ( 5 repetições) seguidos por letras diferentes, na mesma coluna, indicam diferenças significativas entre PJ e PM $(\mathrm{p} \leq 0,05)$. Ausência de letras indica semelhança entre PJ e PM. nd = não detectável.

O maior aporte de P pela serapilheira total produzida na área PM (Tabela 4), que foi decorrente não só da maior produção de serapilheira como também da maior participação de folhas de espécies nativas de Mata Atlântica neste plantio (Tabela 2), ocasionou o aumento da disponibilidade deste nutriente na camada superficial do solo, na estação chuvosa/2010. Contudo, não houve diferença entre as áreas PJ e PM com relação à disponibilidade de $\mathrm{P}$ na camada superficial do solo, nas estações secas estudadas (2008 e 2009), ao passo que a disponibilidade deste nutriente foi menor na área PM, na estação chuvosa/2008. Esta ampla variação nos resultados provavelmente foi decorrente da dinâmica de disponibilidade do $\mathrm{P}$ no solo, que inclui a sua imobilização temporária na biomassa microbiana e, principalmente, a importante adsorção em partículas coloidais em solos altamente intemperizados desenvolvidos sob clima tropical, que tornam 
este elemento indisponível para as plantas (SANTOS; FRANKLIN; LUIZÃO, 2008).

Acredita-se que as concentrações de $\mathrm{Ca}$ e $\mathrm{Mg}$ foram muito baixas no solo superficial de ambas as áreas, as quais sequer foram detectadas no PM, porque tais elementos são pouco móveis nos tecidos vegetais e, portanto, são mais fortemente imobilizados na biomassa das plantas. Sabe-se que a concentração de alguns nutrientes no solo pode diminuir, em função do relativo aumento do seu estoque na biomassa florestal, como resultado do gradativo incremento de biomassa que se processa durante o amadurecimento ecossistêmico (VITOUSEK; SANFORD JUNIOR, 1986). Este padrão foi atestado em florestas tropicais no México (BAUTISTA-CRUZ; CASTILlO, 2005), Porto Rico (LUGO; HELMER, 2004) e em Mata Atlântica no Rio de Janeiro (MORAES et al., 2008). Este quadro ocasionou a crescente acidificação do pH no solo dos plantios de Corymbia citriodora, com o avançar da sucessão secundária de Mata Atlântica. Isto ocorre em função da lixiviação de nutrientes catiônicos, absorção de $\mathrm{Ca}$ e $\mathrm{Mg}$ pela vegetação e a produção de uma serapilheira gradativamente mais ácida, ao longo do desenvolvimento florestal (BAUTISTA-CRUZ; CASTILLO, 2005).

TABELA 2: Produção de serapilheira $\left(\mathrm{Mg} \mathrm{ha}^{-1} \mathrm{ano}^{-1}\right.$, desvio padrão entre parênteses) e participação relativa (\%) das frações, nos Plantios jovem (PJ) e maduro (PM) do eucalipto Corymbia citriodora, Reserva Biológica União, RJ.

TABLE 2: $\quad$ Litterfall $\left(\mathrm{Mg} \mathrm{ha}^{-1}\right.$ year $^{-1}$; standard deviation in parenthesis) and relative contribution (\%) of the litter fractions in young (PJ) and mature (PM) plantations of Corymbia citriodora, União Biological Reserve, RJ state.

\begin{tabular}{l|cc|cc}
\hline \multirow{2}{*}{ Serapilheira } & $\begin{array}{c}\text { Produção } \\
\left(\mathrm{Mg} \mathrm{ha}^{-1} \mathrm{ano}^{-1}\right)\end{array}$ & $\begin{array}{c}\text { Participação } \\
\text { relativa (\%) }\end{array}$ & \begin{tabular}{c} 
Produção $_{\left.\mathrm{Mg} \mathrm{ha}^{-1} \mathrm{ano}^{-1}\right)}$ \\
\cline { 2 - 5 }
\end{tabular} & \multicolumn{2}{c}{$\begin{array}{c}\text { Participação } \\
\text { relativa }(\%)\end{array}$} \\
\hline Folhas de Corymbia citriodora & $2,08 \mathrm{~b}(0,20)$ & 41 & $2,33 \mathrm{a}(0,51)$ & 24 \\
Folhas de espécies nativas & $0,09 \mathrm{~b}(0,12)$ & 2 & $2,69 \mathrm{a}(0,45)$ & 27 \\
Galhos finos e cascas & $2,52 \mathrm{~b}(0,89)$ & 50 & $3,60 \mathrm{a}(1,71)$ & 36 \\
Miscelânea & $0,36 \mathrm{~b}(0,10)$ & 7 & $1,25 \mathrm{a}(0,36)$ & 13 \\
Total & $5,05 \mathrm{~b}(1,06)$ & 100 & $9,91 \mathrm{a}(2,01)$ & 100 \\
\hline
\end{tabular}

Em que: Valores médios ( 5 repetições) seguidos por letras diferentes, na mesma linha, indicam diferenças significativas entre PJ e PM $(\mathrm{p} \leq 0,05)$. Ausência de letras indica semelhança entre PJ e PM.

Os valores de produção anual de serapilheira total e de todas as frações foram significativamente maiores na área PM em relação à área PJ (Tabela 2). Este fato foi decorrente da diferença de idade entre os plantios de Corymbia citriodora estudados, já que a área PM apresenta 23 anos a mais de implantação em comparação ao PJ. Isto implica em uma maior estrutura de toda a comunidade arbórea na primeira área, que abrange não só as árvores de eucalipto como também as nativas de Mata Atlântica. O aumento da produção de serapilheira ao longo do avançar da sucessão secundária foi verificado em diferentes ecossistemas florestais tropicais (WERNECK; PEDRALLI; FARAH, 2001; TOLEDO; PEREIRA; MENEZES, 2002; PINTO; MARQUES, 2003; BARBOSA; FARIA, 2006; PINTO et al., 2008; SCHEER et al., 2009).

Considerando-se a participação relativa das frações na serapilheira total, a ordem decrescente na área PJ foi: galhos finos e cascas $>$ folhas de Corymbia citriodora $>$ miscelânea $>$ folhas de espécies nativas de Mata Atlântica. Já na área PM, esta ordem foi a seguinte: galhos finos e cascas $>$ folhas de espécies nativas $>$ folhas de Corymbia citriodora $>$ miscelânea. Conforme avançou a sucessão secundária, a participação relativa de folhas de Corymbia citriodora e galhos finos e cascas foi diminuída em aproximadamente a metade, enquanto que a de miscelânea e folhas de espécies nativas aumentaram em cerca de 2 e 14 vezes, respectivamente. Em relação apenas à serapilheira foliar, embora as folhas de Corymbia citriodora tenham apresentado elevada participação relativa em ambos os plantios de eucalipto, esta foi aproximadamente o dobro no PJ (96\%) em relação ao PM (46\%). Desta maneira, as folhas de espécies nativas de Mata Atlântica compuseram $4 \%$ e $54 \%$ da serapilheira foliar no PJ e PM, respectivamente. Esta diferença de participação relativa das espécies na serapilheira foliar era esperada, em função do estágio de sucessional mais avançado na área PM (EVARISTO; BRAGA; NASCIMENTO, 2011). 
Chave et al. (2010) observaram, por meio de revisão dos resultados obtidos em 36 estudos realizados em florestas tropicais na América do Sul, que a produção de serapilheira total média para florestas maduras é de $8,6 \mathrm{Mg} \mathrm{ha}^{-1} \mathrm{ano}^{-1}$, valor considerado maior do que o observado em florestas secundárias recémperturbadas $\left(8,0 \mathrm{Mg} \mathrm{ha}^{-1} \mathrm{ano}^{-1}\right)$, sendo que a contribuição média de folhas é de $71 \%$ da serapilheira total, independentemente do estágio sucessional. Portanto, a produção de serapilheira total nas áreas PM e PJ foi maior e menor do que o observado para estes dois tipos de ecossistema, respectivamente, enquanto que a participação relativa da fração folhas em ambos os plantios de eucalipto foi menor ao observado para a média de florestas tropicais, segundo Chave et al. (2010). A produção de serapilheira é uma função da produtividade primária, a qual aumenta proporcionalmente à estrutura florestal, que é maior em estágios sucessionais mais avançados (PINTO; MARQUES, 2003; MARTIN; SHERMAN; FAHEY, 2004; BOEGER; WISNIEWSKI; REISSMANN, 2005).

Contudo, o aumento progressivo da produção de serapilheira ao longo do amadurecimento ecossistêmico não é ilimitado e passa por uma desaceleração durante este processo (BROWN; LUGO, 1990). No México, a produção de serapilheira aumentou progressivamente ao se compararem florestas tropicais secundárias com 15, 45 e 75 anos, mas se igualou na comparação entre uma floresta com 100 anos de idade e aquela com apenas 15 anos de idade (NEGRETE-YANKELEVICH et al., 2006). Este fato ocorre em virtude da estabilização da produtividade primária em florestas em estágios sucessionais mais avançados (WERNECK; PEDRALLI; FARAH, 2001). Desta maneira, na comparação da produção de serapilheira entre florestas em estágios intermediário e avançado de sucessão secundária, pode-se observar tanto a ausência de diferença (WERNECK; PEDRALLI; FARAH, 2001) quanto a maior produção no estágio intermediário (PINTO; MARQUES, 2003).

A maior queda da serapilheira total ocorreu durante o período chuvoso (setembro a abril), tanto na área de PJ quanto na área PM (Figura 1). Em florestas que ocorrem em áreas de clima tropical úmido, como é o caso da Reserva Biológica União, não ocorre um período crítico de seca e, desta maneira, as maiores taxas de queda de serapilheira geralmente são verificadas durante o período chuvoso, em razão da incidência de ventos com maior velocidade (PINTO; MARQUES, 2003; CALVI; PEREIRA; ESPÍNDULA JÚNIOR, 2009; SCHEER et al., 2009). Em ambos os plantios de Corymbia citriodora estudados foram encontrados galhos e folhas verdes em alguns coletores de serapilheira, em datas de coleta compreendidas no período de maior precipitação pluviométrica. Isto demonstrou a influência do efeito mecânico de ventos e chuvas mais fortes na maior queda de serapilheira, nesta época.

De uma maneira geral, as concentrações de $\mathrm{N}$ total e $\mathrm{Mg}$ foram maiores na serapilheira total e em

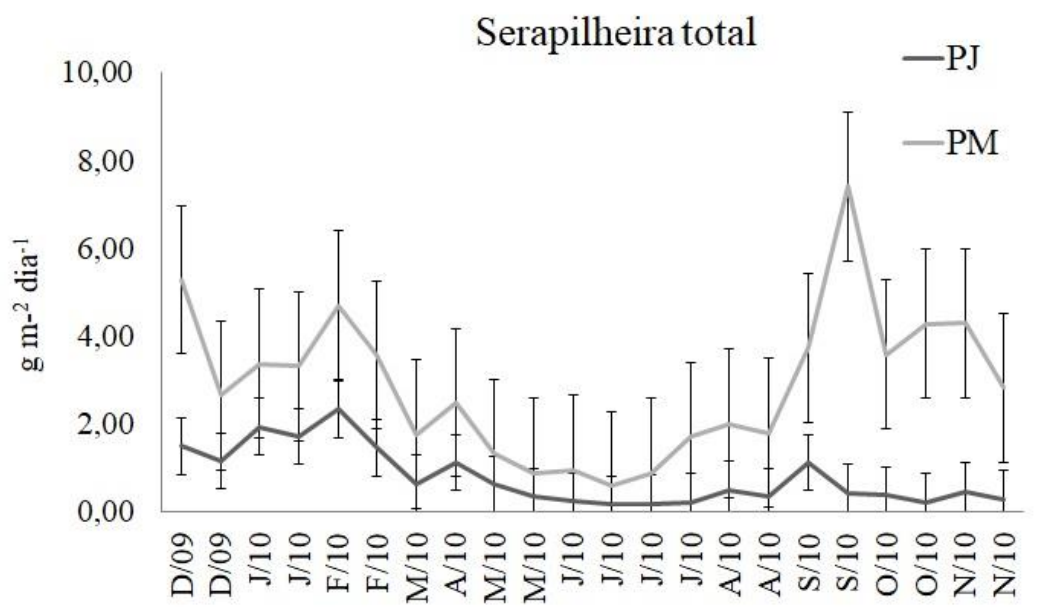

FIGURA 1: Valores médios diários $\left(\mathrm{g} \mathrm{m}^{-2} \mathrm{dia}^{-1} \pm\right.$ desvio padrão) da produção anual de serapilheira total nos Plantios jovem (PJ) e maduro (PM) do eucalipto Corymbia citriodora, na Reserva Biológica União, RJ.

FIGURE 1: Mean daily values $\left(\mathrm{g} \mathrm{m}^{-2}\right.$ day $^{-1} \pm$ standard deviation) of total annual litterfall in young (PJ) and mature (PM) plantations of Corymbia citriodora, União Biological Reserve, RJ state. 
praticamente todas as frações de serapilheira, no PM (Tabela 3). O oposto, ou seja, maiores concentrações na serapilheira total e em frações na área PJ, foi verificado para $\mathrm{Pe} \mathrm{Ca}$. Como reflexo do resultado para o N, os valores da razão $\mathrm{C} / \mathrm{N}$ foram menores na serapilheira anual total e em todas as frações no $\mathrm{PM}$, em relação ao PJ. Com relação ao K, somente houve diferença significativa em folhas da serapilheira de Corymbia citriodora, cuja concentração foi maior no PM do que no PJ. Não houve diferenças entre os estágios de sucessionais com relação às concentrações de $\mathrm{C}$ total na serapilheira total e frações.

$\mathrm{O}$ aumento das concentrações de $\mathrm{N}$ com o desenvolvimento sucessional variou de $40 \%$ (folhas de Corymbia citriodora) a $51 \%$ (folhas de espécies nativas), o qual resultou em aumento de $81 \%$ na serapilheira total. O mesmo foi constatado para $\mathrm{Mg}$, cujo aumento da concentração variou entre $16 \%$ (miscelânea) e $62 \%$ (folhas de espécies nativas e galhos finos e cascas), com um aumento de $44 \%$ na serapilheira total. Por outro lado, a diminuição da razão $\mathrm{C} / \mathrm{N}$ com o avançar da sucessão variou de $40 \%$ (folhas de Corymbia citriodora) a 106\% (galhos finos e cascas), e ocasionou a diminuição de 123\% na serapilheira total. Este padrão se repetiu para as concentrações de $\mathrm{Ca}$, que variaram entre $29 \%$ (miscelânea) e $114 \%$ (folhas de Corymbia citriodora) e levaram à diminuição de $61 \%$ na serapilheira total; e $\mathrm{P}$, que variou de $49 \%$ (folhas de Corymbia citriodora) a 136\% (folhas de espécies nativas), com diminuição de $30 \%$ na serapilheira total. As modificações observadas na qualidade química da serapilheira foliar de Corymbia citriodora, na comparação entre os dois plantios, foram provavelmente ocasionadas pela presença de outras espécies arbóreas (HOSSEINI et al., 2011).

TABELA 3: Atributos químicos da serapilheira (desvio padrão) nos Plantios jovem (PJ) e maduro (PM) do eucalipto Corymbia citriodora, Reserva Biológica União, RJ.

TABLE 3: Litterfall chemical attributes (standard deviation) in young (PJ) and mature (PM) plantations of Corymbia citriodora, União Biological Reserve, RJ state.

\begin{tabular}{|c|c|c|c|c|c|c|c|c|}
\hline \multirow[t]{2}{*}{ Serapilheira } & \multicolumn{2}{|c|}{$\mathrm{C}$} & \multicolumn{2}{|c|}{ N } & \multicolumn{2}{|c|}{$\mathrm{C} / \mathrm{N}$} & \multicolumn{2}{|c|}{$\begin{array}{c}\mathrm{P} \\
--\mathrm{mg} \mathrm{g}^{-1}-- \\
\end{array}$} \\
\hline & $\mathrm{PJ}$ & PM & $\mathrm{PJ}$ & PM & PJ & PM & PJ & PM \\
\hline Folhas de Corymbia & 48,43 & 49,40 & $0,63 a$ & $0,88 \mathrm{~b}$ & $84 a$ & $60 \mathrm{~b}$ & $0,97 \mathrm{a}$ & $0,65 b$ \\
\hline citriodora & $(2,82)$ & $(3,04)$ & $(0,28)$ & $(0,23)$ & (19) & $(16)$ & $(0,35)$ & $(0,16)$ \\
\hline \multirow[t]{2}{*}{ Folhas de espécies nativas } & 47,19 & 47,47 & $1,06 a$ & $1,60 \mathrm{~b}$ & $49 a$ & $31 b$ & $1,77 \mathrm{a}$ & $0,75 b$ \\
\hline & $(1,75)$ & $(0,59)$ & $(0,31)$ & $(0,25)$ & $(17)$ & $(4)$ & $(1,14)$ & $(0,27)$ \\
\hline \multirow[t]{2}{*}{ Galhos finos e cascas } & 45,63 & 45,69 & 0,32 & 0,49 & $255 \mathrm{a}$ & $124 b$ & 0,35 & 0,30 \\
\hline & $(0,43)$ & $(0,95)$ & $(0,28)$ & $(0,28)$ & $(185)$ & $(72)$ & $(0,26)$ & $(0,12)$ \\
\hline \multirow[t]{2}{*}{ Miscelânea } & 48,47 & 48,10 & $1,01 \mathrm{a}$ & $1,45 b$ & $57 a$ & $37 b$ & 1,20 & 1,25 \\
\hline & $(3,00)$ & $(1,07)$ & $(0,56)$ & $(0,68)$ & $(21)$ & $(10)$ & $(0,49)$ & $(0,21)$ \\
\hline \multirow[t]{2}{*}{ Total } & 46,62 & 47,61 & $0,70 \mathrm{a}$ & $1,27 b$ & $116 \mathrm{a}$ & $52 b$ & $0,95 \mathrm{a}$ & $0,73 b$ \\
\hline & $(1,44)$ & $(0,89)$ & $(0,19)$ & $(0,14)$ & $(52)$ & $(12)$ & $(0,41)$ & $(0,11)$ \\
\hline \multirow[t]{3}{*}{ Serapilheira } & \multicolumn{2}{|c|}{$\mathrm{K}$} & \multicolumn{2}{|c|}{$\mathrm{Ca}$} & \multirow{2}{*}{\multicolumn{2}{|c|}{$\mathrm{Mg}$}} & & \\
\hline & \multicolumn{4}{|c|}{--------------------'mg g } & & & & \\
\hline & PJ & PM & PJ & PM & PJ & PM & & \\
\hline Folhas de Corymbia & $3,23 a$ & $4,69 \mathrm{~b}$ & $17,14 \mathrm{a}$ & $8,00 \mathrm{~b}$ & $3,67 a$ & $3,17 b$ & & \\
\hline citriodora & $(2,19)$ & $(3,03)$ & $(2,28)$ & $(1,10)$ & $(0,52)$ & $(0,53)$ & & \\
\hline \multirow[t]{2}{*}{ Folhas de espécies nativas } & 4,01 & 4,46 & $14,30 \mathrm{a}$ & $9,36 \mathrm{~b}$ & $4,87 \mathrm{a}$ & $7,90 \mathrm{~b}$ & & \\
\hline & $(1,75)$ & $(1,21)$ & $(4,16)$ & $(4,90)$ & $(1,08)$ & $(1,85)$ & & \\
\hline \multirow[t]{2}{*}{ Galhos finos e cascas } & 2,37 & 2,48 & $12,82 \mathrm{a}$ & $5,07 \mathrm{~b}$ & $2,10 \mathrm{a}$ & $2,43 b$ & & \\
\hline & $(1,30)$ & $(2,31)$ & $(7,02)$ & $(1,74)$ & $(0,42)$ & $(0,52)$ & & \\
\hline \multirow[t]{2}{*}{ Miscelânea } & 5,23 & 5,95 & $7,25 a$ & $5,60 \mathrm{~b}$ & $2,96 a$ & $4,25 b$ & & \\
\hline & $(2,12)$ & $(3,02)$ & $(1,35)$ & $(1,28)$ & $(0,54)$ & $(1,11)$ & & \\
\hline \multirow[t]{2}{*}{ Total } & 3,71 & 4,38 & $12,69 \mathrm{a}$ & $7,86 b$ & $3,16 a$ & $5,54 b$ & & \\
\hline & $(1,62)$ & $(2,26)$ & $(2,14)$ & $(1,34)$ & $(0,48)$ & $(0,81)$ & & \\
\hline
\end{tabular}

Em que: Valores médios ( 5 repetições) seguidos por letras diferentes, na mesma linha, indicam diferenças significativas entre PJ e PM $(\mathrm{p} \leq 0,05)$. Ausência de letras indica semelhança entre PJ e PM. 
A maior qualidade química da serapilheira total na área PM foi um reflexo de dois fatores: maior participação de espécies nativas de Mata Atlântica na produção de serapilheira (serapilheira mais heterogênea), e aumento das concentrações de $\mathrm{N}$ e $\mathrm{Mg}$ e diminuição da razão $\mathrm{C} / \mathrm{N}$ na serapilheira foliar das espécies nativas, ao longo do processo de sucessão secundária. Este incremento da qualidade química da serapilheira produzida em florestas em estágio sucessional mais avançado, quando comparado com a serapilheira de florestas mais jovens, também foi verificado em florestas tropicais na Amazônia brasileira (VASCONCELOS; LAURANCE, 2005) e em Mata Atlântica (TOLEDO; PEREIRA; MENEZES, 2002; PINTO; MARQUES, 2003; BARBOSA; FARIA, 2006; CALVI; PEREIRA; ESPÍNDULA JÚNIOR, 2009; PINTO et al., 2009).

Esse padrão é resultado da menor esclerofilia (PINTO; MARQUES, 2003; DICKOW; MARQUES; PINTO, 2009) e da maior concentração de nutrientes (BOEGER; WISNIEWSKI; REISSMANN, 2005) que as folhas das espécies arbóreas presentes em estágios sucessionais mais avançados apresentam, em relação às folhas das espécies típicas do início da sucessão. Existe uma variação entre as espécies florestais com relação à qualidade química da serapilheira foliar e, desta maneira, a composição de espécies de uma floresta ou plantio florestal geralmente influencia fortemente a ciclagem de nutrientes (PRESCOTT, 2002).

Os aportes de todos os elementos $(\mathrm{C}, \mathrm{N}, \mathrm{P}, \mathrm{K}, \mathrm{Ca}$ e $\mathrm{Mg}$ ) foram maiores nas folhas da serapilheira de espécies nativas de Mata Atlântica e na miscelânea na área PM, em comparação com a área PJ. Este padrão se manteve para a serapilheira total, com exceção do Ca, uma vez que não houve diferenças para seu aporte, na comparação entre as áreas PJ e PM (Tabela 4). A participação de folhas da serapilheira de Corymbia citriodora foi relevante para o aporte total de todos os nutrientes, em ambos os plantios desta espécie de eucalipto. Contudo, isto ocorreu de maneira bem mais importante no PJ (42\% do aporte total de N; $59 \%$ de P; $54 \%$ de $\mathrm{K} ; 58 \%$ de $\mathrm{Ca} ; 50 \%$ de $\mathrm{Mg}$ ), no qual a contribuição desta fração de serapilheira no aporte dos nutrientes foi o dobro ou mais do que o dobro do observado no PM ( $20 \%$ do aporte total de N; $21 \%$ de P; $28 \%$ de $\mathrm{K} ; 22 \%$ de $\mathrm{Ca} ; 14 \%$ de $\mathrm{Mg}$ ).

TABELA 4: Aporte de elementos na serapilheira $\left(\mathrm{kg} \mathrm{ha}^{-1}\right.$, desvio padrão em parêntesis) nos plantios jovem (PJ) e maduro (PM) do eucalipto Corymbia citriodora, Reserva Biológica União, RJ.

TABLE 4: Element input by litterfall $\left(\mathrm{kg} \mathrm{ha}^{-1}\right.$, standard deviation in parenthesis) in young (PJ) and mature (PM) plantations of Corymbia citriodora, União Biological Reserve, RJ state.

\begin{tabular}{|c|c|c|c|c|c|c|}
\hline \multirow{3}{*}{ Serapilheira } & \multicolumn{2}{|c|}{$\mathrm{C}$} & \multicolumn{2}{|c|}{$\mathrm{N}$} & \multicolumn{2}{|c|}{$\mathrm{P}$} \\
\hline & & ---kg ha- & & & \\
\hline & PJ & PM & PJ & PM & $\mathrm{PJ}$ & PM \\
\hline Folhas de Corymbia citriodora & $\begin{array}{c}1677,25 \\
(102059)\end{array}$ & 1545,20 & 21,61 & 31,43 & $0,34 \mathrm{a}$ & $0,20 \mathrm{~b}$ \\
\hline \multirow{2}{*}{ Folhas de espécies nativas } & $137,90 \mathrm{a}$ & $2143,59 \mathrm{~b}$ & $2,79 \mathrm{a}$ & $68,33 b$ & $0,04 \mathrm{a}$ & $0,12 b$ \\
\hline & $(90,04)$ & $(585,41)$ & $(1,60)$ & $(17,24)$ & $(0,04)$ & $(0,05)$ \\
\hline \multirow{2}{*}{ Galhos finos e cascas } & $1917,29 a$ & $2725,52 b$ & 22,02 & 25,44 & 0,13 & 0,16 \\
\hline & $(2082,85)$ & $(1670,19)$ & $(33,10)$ & $(18,99)$ & $(0,13)$ & $(0,16)$ \\
\hline Miscelânea & $287,28 \mathrm{a}$ & $1008,40 \mathrm{~b}$ & $5,85 \mathrm{a}$ & $32,91 \mathrm{~b}$ & $0,07 a$ & $0,26 \mathrm{~b}$ \\
\hline \multirow[b]{2}{*}{ Total } & $\begin{array}{c}(54,90) \\
3056677_{2}\end{array}$ & $\begin{array}{l}(364,66) \\
745273 h\end{array}$ & $\begin{array}{l}(0,31) \\
6308\end{array}$ & $\begin{array}{l}(25,85) \\
10708 \mathrm{~h}\end{array}$ & $(0,04)$ & $(0,17)$ \\
\hline & $(2092,29)$ & $\begin{array}{l}1452, / 30 \\
(2590,46)\end{array}$ & $(47,98)$ & $(70,17)$ & $(0,32)$ & $(0,08)$ \\
\hline \multirow{3}{*}{ Serapilheira } & \multicolumn{2}{|c|}{$\mathrm{K}$} & \multirow{2}{*}{\multicolumn{2}{|c|}{$\begin{array}{c}\mathrm{Ca} \\
-\mathrm{kg} \mathrm{ha}^{-1}-\end{array}$}} & \multirow{2}{*}{\multicolumn{2}{|c|}{$\mathrm{Mg}$}} \\
\hline & & & & & \\
\hline & PJ & PM & PJ & PM & PJ & PM \\
\hline Folhas de Corymbia citriodora & $\begin{array}{c}1,36 \\
(1,44)\end{array}$ & $\begin{array}{c}1,55 \\
(1,50)\end{array}$ & $\begin{array}{l}5,69 \mathrm{a} \\
(3,38)\end{array}$ & $\begin{array}{l}2,41 \mathrm{~b} \\
(1,04)\end{array}$ & $\begin{array}{c}1,31 \\
(0,87)\end{array}$ & $\begin{array}{c}0,97 \\
(0,46)\end{array}$ \\
\hline \multirow{2}{*}{ Folhas de espécies nativas } & $0,11 \mathrm{a}$ & $0,57 \mathrm{~b}$ & $0,36 a$ & $1,93 \mathrm{~b}$ & $0,12 \mathrm{a}$ & $1,33 b$ \\
\hline & $(0,12)$ & $(0,34)$ & $(0,33)$ & $(0,80)$ & $(0,09)$ & $(0,59)$ \\
\hline \multirow{2}{*}{ Galhos finos e cascas } & 0,71 & 1,11 & 3,32 & 2,68 & 0,99 & 1,32 \\
\hline & $(0,66)$ & $(1,16)$ & $(2,11)$ & $(1,83)$ & $(1,12)$ & $(0,92)$ \\
\hline
\end{tabular}


TABELA 4: Continuação...

TABLE 4: Continued...

\begin{tabular}{|c|c|c|c|c|c|c|}
\hline \multirow{3}{*}{ Serapilheira } & \multicolumn{2}{|c|}{$\mathrm{K}$} & \multicolumn{2}{|c|}{$\mathrm{Ca}$} & \multicolumn{2}{|c|}{$\mathrm{Mg}$} \\
\hline & & --------- & --kg ha & ------" & --- & \\
\hline & PJ & PM & PJ & PM & PJ & PM \\
\hline Miscelânea & $\begin{array}{c}0,33 a \\
(0,23)\end{array}$ & $\begin{array}{l}1,38 b \\
(1,33)\end{array}$ & $\begin{array}{c}0,42 \mathrm{a} \\
(0,19)\end{array}$ & $\begin{array}{c}1,19 b \\
(0,72)\end{array}$ & $\begin{array}{c}0,18 \mathrm{a} \\
(0,09)\end{array}$ & $\begin{array}{l}0,93 b \\
(0,63)\end{array}$ \\
\hline Total & $\begin{array}{c}2,46 a \\
(1,86)\end{array}$ & $\begin{array}{l}5,88 \mathrm{~b} \\
(4,11)\end{array}$ & $\begin{array}{c}9,61 \\
(4,60)\end{array}$ & $\begin{array}{l}10,85 \\
(4,19)\end{array}$ & $\begin{array}{c}2,53 a \\
(1,42)\end{array}$ & $\begin{array}{l}6,53 b \\
(2,43)\end{array}$ \\
\hline
\end{tabular}

Em que: Valores médios ( 5 repetições) seguidos por letras diferentes, na mesma linha, indicam diferenças significativas entre PJ e PM $(\mathrm{p} \leq 0,05)$. Ausência de letras indica semelhança entre PJ e PM.

Em contrapartida, a contribuição das folhas da serapilheira de espécies nativas de Mata Atlântica no aporte de todos os elementos foi pequena na área PJ ( $5 \%$ do aporte total de N; 7\% de P; $5 \%$ de K; 4\% de $\mathrm{Ca} ; 5 \%$ de $\mathrm{Mg}$ ) e bastante relevante na área de PM (43\% do aporte total de N; $34 \%$ de P; 32\% de K; $43 \%$ de $\mathrm{Ca} ; 52 \%$ de $\mathrm{Mg}$ ). Isto foi decorrente da diminuição e do aumento da importância relativa de folhas de Corymbia citriodora e de espécies nativas de Mata Atlântica, respectivamente, no decorrer da sucessão secundária nas áreas estudadas. O maior aporte de todos os elementos minerais na área de PM, com exceção do $\mathrm{Ca}$, ocorreu, principalmente, em virtude da maior produção de serapilheira total no referido plantio (aproximadamente o dobro), quando comparado ao PJ. Este padrão de maior aporte de nutrientes para o solo ocasionado pela maior produção de serapilheira total em ecossistemas florestais mais maduros, do que naqueles mais jovens, também foi observado em florestas tropicais na República Dominicana (MARTIN; SHERMAN; FAHEY, 2004) e em áreas de Mata Atlântica no Paraná (PINTO; MARQUES, 2003), Rio de Janeiro (BARBOSA; FARIA, 2006) e Minas Gerais (PINTO et al., 2009).

Dentro de cada plantio de Corymbia citriodora, o maior aporte de nutrientes também ocorreu em função das frações com maior participação na serapilheira anual total. Assim, na área PJ, o maior aporte de todos os nutrientes ocorreu via folhas da serapilheira de Corymbia citriodora, que foi a fração de maior produção, embora as maiores concentrações de N, $\mathrm{P}, \mathrm{K} \mathrm{e} \mathrm{Mg}$ tenham sido verificadas em folhas da serapilheira de espécies nativas de Mata Atlântica e/ou na miscelânea. Resultado semelhante foi observado no PM, no qual o maior aporte de $\mathrm{K}, \mathrm{Ca}$ e $\mathrm{Mg}$ foi proporcionado por folhas da serapilheira de Corymbia citriodora e/ou galhos finos e cascas, em virtude de sua elevada produção, apesar das maiores concentrações destes nutrientes terem sido constatadas, de uma maneira geral, em folhas da serapilheira de espécies nativas de Mata Atlântica, neste plantio. Em contrapartida, o aporte de P no PM divergiu do padrão acima discutido. A maior concentração e também o maior aporte de P ocorreram na fração miscelânea, que incluiu as estruturas reprodutivas (flores e frutos), apesar de tal fração ter apresentado a menor participação na produção de serapilheira total neste plantio de Corymbia citriodora.

Portanto, nem sempre o maior aporte de nutrientes está conjugado à maior produção de serapilheira. Esta situação também foi encontrada em um trabalho que estudou a produção de serapilheira e o retorno de nutrientes por esta via, em plantios monoespecíficos com dez espécies florestais diferentes, em Porto Rico (CUEVAS; LUGO, 1998). Estes autores documentaram que Pinus caribaea Barrett \& Golfari figurou entre as três espécies que mais produziram serapilheira total, mas foi uma das que aportou as menores quantidades de $\mathrm{N}, \mathrm{Ca}$ e $\mathrm{Mg}$ para o solo, devido às baixas concentrações destes nutrientes em tal material. Em contrapartida, Hernandia sonora L., que produziu menos serapilheira total anual do que Pinus caribaea, aportou maiores quantidades de N, P, K e Mg do que esta última espécie, em função das maiores concentrações destes elementos na serapilheira.

De uma maneira geral, florestas ou plantios florestais com maior número de espécies, sejam elas nativas ou não, tendem a apresentar maior potencial de retorno de nutrientes pela serapilheira total para 0 solo, do que plantios monoespecíficos (WANG; WANG; HUANG, 2008; WANG et al., 2010). Isto ocorre porque o aporte de nutrientes via serapilheira em ecossistemas florestais varia conforme a composição de espécies, já que a natureza química da serapilheira, que considera a concentração de nutrientes e a razão C/N, varia entre as espécies florestais (PRESCOTT, 2002; TRIPATHI; PANDEY; TRIPATHI, 2009). Em florestas 
mais heterogêneas ocorre a combinação de espécies que apresentam diferentes estratégias de ciclagem de nutrientes, as quais se tornam complementares em conjunto, o que concorre para o enriquecimento do status nutricional dos solos (GAMA-RODRIGUES; GAMA-RODRIGUES; BARROS, 2008). Estudos comparando plantios puros (monoespecíficos) com plantios mistos demonstraram que o aumento da variedade de espécies foi positivo para o incremento do aporte de nutrientes pela serapilheira (GAMARODRIGUES; GAMA-RODRIGUES; BARROS, 2008; WANG; WANG; HUANG, 2008; WANG et al., 2010).

\section{CONCLUSÕES}

No solo superficial, com o avançar da sucessão secundária, houve o incremento da concentração de $\mathrm{Mn}$ e de $\mathrm{C}$ e $\mathrm{N}$ totais, enquanto a concentração de $\mathrm{K}$, Fe e $\mathrm{Zn}$ diminuiu e não se observou um padrão claro de variação para $\mathrm{P}$ e $\mathrm{Cu}$.

$\mathrm{Na}$ serapilheira, as concentrações de $\mathrm{N}$ total e $\mathrm{Mg}$ aumentaram, enquanto as de $\mathrm{P}$ e Ca diminuíram, ao passo que as de $\mathrm{C}$ total não variaram, durante o desenvolvimento ecossistêmico.

A produção de serapilheira e o aporte de todos os elementos ao solo $(\mathrm{C}, \mathrm{N}, \mathrm{P}, \mathrm{K} \mathrm{e} \mathrm{Mg})$ foram maiores no estágio sucessional mais avançado, com exceção do $\mathrm{Ca}$, para o qual não houve diferença significativa na comparação entre os estágios de sucessão.

\section{REFERÊNCIAS}

ALLEN, S. E. Chemical analysis of ecological materials. Oxford: Blackwell Scientific Publications, 1989. $380 \mathrm{p}$.

BARBOSA, J. H. C.; FARIA, S. M. Aporte de serrapilheira ao solo em estágios sucessionais florestais na Reserva Biológica de Poço das Antas, Rio de Janeiro, Brasil. Rodriguésia, Rio de Janeiro, v. 57, n. 3, p. 461-476, 2006.

BAUTISTA-CRUZ, A.; CASTILLO, R. F. Soil changes during secondary succession in a tropical montane cloud forest area. Soil Science Society of America Journal, Washington, v. 69, p. 906-914, 2005.

BOEGER, M. R. T.; WISNIEWSKI, C.; REISSMANN, C. B. Nutrientes foliares de espécies arbóreas de três estádios sucessionais de floresta ombrófila densa no sul do Brasil. Acta Botanica Brasilica, Belo Horizonte, v. 19, n. 1, p. 167-181, 2005.

BROWN, S.; LUGO, A. E. Tropical secondary forests. Journal of Tropical Ecology, Cambridge, v. 6, p. 1-32, 1990.

CALVI, G. P.; PEREIRA, M. G.; ESPÍNDULA JÚNIOR, A. Produção de serapilheira e aporte de nutrientes em áreas de Floresta Atlântica em Santa Maria de Jetibá, ES. Ciência Florestal, Santa Maria, v. 19, n. 2, p. 131-138, 2009.

CAMARA, R.; CORREIA, M. E. F.; VILLELA, D. M. Effects of eucalyptus plantations on soil arthropod communities in a Brazilian Atlantic Forest conservation unit. Bioscience Journal, Uberlândia, v. 28, n. 3, p. 445-455, 2012.

CHAVE, J. et al. Regional and seasonal patterns of litterfall in tropical South America. Biogeosciences, Munich, v. 7, p. 43-55, 2010.

CUEVAS, E.; LUGO, A. L. Dynamics of organic matter and nutrient return from litterfall in stands of ten tropical tree plantation species. Forest Ecology and Management, Netherlands, v. 112, p. 263-279, 1998. CULLINGS, K. W. et al. Effects of litter addition on ectomycorrhizal associates of a lodgepole pine (Pinus contorta) stand in Yellowstone National Park. Applied and Environmental Microbiology, Washington, v. 69, n. 7, p. 3772-3776, 2003.

DICKOW, K. M. C.; MARQUES, R.; PINTO, C. B. Lixiviação de nutrientes da serapilheira recémdepositada em sucessão ecológica na Floresta Atlântica, litoral do Paraná. Floresta, Curitiba, v. 39, n. 1. p. 145-156, 2009.

EMBRAPA. Manual de métodos de análise de solo. Rio de Janeiro: Centro Nacional de Pesquisa em Solos, 1997. 212 p.

EVARISTO, V. T.; BRAGA, J. M. A.; NASCIMENTO, M. T. Atlantic Forest regeneration in abandoned 
plantations of eucalypt (Corymbia citriodora (Hook.) K. D. Hill and L. A. S. Johnson) in Rio de Janeiro, Brazil. Interciencia, Caracas, v. 36, n. 6, p. 431-436, 2011.

FERREIRA, S. J. F. et al. Nutrientes na solução do solo em floresta de terra firme na Amazônia Central submetida à extração seletiva de madeira. Acta Amazonica, Manaus, v. 36, n. 1, p. 59-68, 2006.

GAMA-RODRIGUES, A. C.; GAMA-RODRIGUES, E. F.; BARROS, N. F. Balanço de carbono e nutrientes em plantio puro e misto de espécies florestais nativas no sudeste da Bahia. Revista Brasileira de Ciência do Solo, Viçosa, MG, v. 32, n. 3, p. 1165-1179, 2008.

HOSSEINI, S. M. et al. Comparison of growth, nutrition and soil properties of pure stands of Quercus castaneifolia C. A. Mey. and mixed with Carpinus betulus L. in the Hyrcanian forests of Iran. Ecologia Balkanica, Plovdiv, v. 3, n. 1, p. 33-49, 2011.

IBAMA. Plano de recuperação ambiental dos eucaliptais da Reserva Biológica União. Rio das Ostras: Reserva Biológica União; Associação Mico-leão Dourado; Critical Ecosystem Partnership Fund, 2007. 142 p.

JIA, G. et al. Microbial biomass and nutrients in soil at the different stages of secondary forest succession in Ziwulin, northwest China. Forest Ecology and Management, Netherlands, v. 217, p. 117-125, 2005.

KÖPPEN, W. Climatologia: con un estudio de los climas de la Tierra. Mexico: Fondo de Cultura Economica, 1948. $478 \mathrm{p}$.

LUGO, A. E.; HELMER, E. Emerging forests on abandoned land: Puerto Rico's new forests. Forest Ecology and Management, Netherlands, v. 190, p. 145-161, 2004.

MARTIN, P. H.; SHERMAN, R. E.; FAHEY, T. J. Forty years of tropical forest recovery from agriculture: structure and floristics of secondary and old-growth riparian forests in the Dominican Republic. Biotropica, Hoboken, v. 36, n. 3, p. 297-317, 2004.

MIRANDA, C. C.; CANELLAS, I. P.; NASCIMENTO, M. T. Caracterização da matéria orgânica do solo em fragmentos de Mata Atlântica e plantios abandonados de eucalipto, Reserva Biológica União, RJ. Revista Brasileira de Ciência do Solo, Viçosa, MG, v. 31, n. 5, p. 905-916, 2007.

MORAES, L. F. D. et al. Características do solo na restauração de áreas degradadas na Reserva Biológica de Poço das Antas, RJ. Ciência Florestal, Santa Maria, v. 18, n. 2, p. 193-206, 2008.

NANNIPIERI, P. et al. Microbial diversity and soil functions. European Journal of Soil Science, Malden, v. 54, p. 655-670, 2003.

NEGRETE-YANKELEVICH, S. et al. Successional changes in soil, litter and macroinvertebrate parameters following selective logging in a Mexican Cloud Forest. Applied Soil Ecology, Netherlands, v. 35, p. 340355, 2007.

NEGRETE-YANKELEVICH, S. et al. Spatial patchiness of litter, nutrients and macroinvertebrates during secondary succession in a Tropical Montane Cloud Forest in Mexico. Plant and Soil, Netherlands, v. 286, p. 123-139, 2006.

$\mathrm{NOH}$, N. J. et al. Carbon and nitrogen storage in an age-sequence of Pinus densiflora stands in Korea. Science China, Berlin, v. 53, n. 7, p. 822-830, 2010.

PAOLI, G. D.; CURRAN, L. M.;ZAK, D. R. Soil nutrients and beta diversity in the Bornean Dipterocarpaceae: evidence for niche partitioning by tropical rain forest trees. Journal of Ecology, London, v. 94, p. 157-170, 2006.

PINTO, C. B.; MARQUES, R. Aporte de nutrientes por frações da serapilheira em sucessão ecológica de um ecossistema da Floresta Atlântica. Revista Floresta, Curitiba, v. 33, n. 3, p. 257-264, 2003.

PINTO, S. I. C. et al. Ciclagem de nutrientes em dois trechos de Floresta Estacional Semidecidual na Reserva Florestal Mata do Paraíso em viçosa, MG, Brasil. Revista Árvore, Viçosa, MG, v. 33, n. 4, p. 653663, 2009.

PINTO, S. I. C. et al. Produção de serapilheira em dois estádios sucessionais de Floresta Estacional Semidecidual na Reserva Mata do Paraíso, em Viçosa, MG. Revista Árvore, Viçosa, MG, v. 32, n. 3, p. 545-556, 2008.

PRESCOTT, C. E. The influence of the forest canopy on nutrient cycling. Tree Physiology, Victoria, v. 22, p. 1193-1200, 2002.

SANTOS, E. M. R.; FRANKLIN, E.; LUIZÃO, F. J. Litter manipulation and associated invertebrate fauna in secondary forest, central Amazonia, Brazil. Acta Oecologica, Netherlands, v. 34, p. 274-284, 2008. 
SCHEER, M. B. et al. Patterns of litter production in a secondary alluvial Atlantic Rain Forest in southern Brazil. Revista Brasileira Botânica, São Paulo, v. 32, n. 4, p. 805-817, 2009.

TOLEDO, L. O.; PEREIRA, M. G.; MENEZES, C. E. G. Produção de serapilheira e transferência de nutrientes em florestas secundárias localizadas na região de Pinheiral, RJ. Ciência Florestal, Santa Maria, v. 12, n. 2, p. 9-16, 2002.

TRIPATHI, O. P.; PANDEY, H. N.; TRIPATHI, R. S. Litter production, decomposition and physico-chemical properties of soil in 3 developed agroforestry systems of Meghalaya, Northeast India. African Journal of Plant Science, Nairobi, v. 3, n. 8, p. 160-167, 2009.

VASCONCELOS, H. L.; LAURANCE, W. F. Influence of habitat, litter type, and soil invertebrates on leaflitter decomposition in a fragmented Amazonian landscape. Oecologia, Netherlands, v. 144, p. 456-462, 2005.

VITOUSEK, P. M.; SANFORD JUNIOR, R. L. Nutrient cycling in moist tropical forests. Annual Review of Ecology and Systematics, Palo Alto, v. 17, p. 137-167, 1986.

WANG, Q. et al. Conversion of secondary broadleaved forest into Chinese fir plantation alters litter production and potential nutrient returns. Plant Ecology, Netherlands, v. 209, p. 269-278, 2010.

WANG, Q.; WANG, S.; HUANG, Y. Comparisons of litterfall, litter decomposition and nutrient return in a monoculture Cunninghamia lanceolata and a mixed stand in southern China. Forest Ecology and Management, Netherlands, v. 255, p. 1210-1218, 2008.

WERNECK, M. S.; PEDRALLI, G.; FARAH, L. Produção de serapilheira em três trechos de uma floresta semidecídua com diferentes graus de perturbação na Estação Ecológica do Tripuí, Ouro Preto, MG.

Revista Brasileira de Botânica, São Paulo, v. 24, n. 2, p. 195-198, 2001.

ZAR, J. H. Biostatistical Analysis. New Jersey: Prentice Hall, 1996. 662 p. 